\title{
Functional SNP in the 3'UTR of PON1 is Associated with the Risk of Calcific Aortic Valve Stenosis via MiR-616
}

\author{
Zhengjun Wang $^{\mathrm{a}}$ Shiqiao Chen ${ }^{\mathrm{b}}$ Mei Zhu ${ }^{\mathrm{c}}$ Wenlong Zhang ${ }^{\mathrm{a}}$ Haizhou Zhang ${ }^{\mathrm{a}}$ \\ Hongxin Lia Chengwei Zou ${ }^{a}$
}

aDepartment of Cardiovascular Surgery, Shandong Provincial Hospital Affiliated to Shandong University, Jinan, Shandong, 'bepartment of Coronary Care Unit, Shandong Provincial Hospital Affiliated to Shandong University, Jinan, Shandong, 'Department of Cardiovascular Ultrasound, Shandong Provincial Hospital Affiliated to Shandong University, Jinan, China

\section{Key Words}

Single nucleotide polymorphism (SNP) • MicroRNA-616 • PON1 • Calcific aortic valve stenosis

\begin{abstract}
Background/Aims: Previous studies have examined the associations between the single nucleotide polymorphism in the Paraoxonase 1 (PON1) gene and development of calcific aortic valve stenosis (CAVS). The association between functional SNP in 3'UTR of PON1 and the risk of CAVS, however, is unclear. In this study, we investigated the role of SNP in the regulation of PON1 expression via miR-616, as well as the association of SNP with the risk of CAVS. Methods: Two hundred and sixteen patients with CAVS and 243 CAVS-free participants were recruited in this study. They all obtained transthoracic echocardiogram and the ejection fraction (EF) and aortic valve area were recorded and analyzed. The PON1 expression were measured by western blot, Quantitative Real-Time Polymerase Chain Reaction were used to examine the transcriptional activity of miR-616 and PON1. Differences between CVAS patients and controls in terms of genotype frequency distribution and the estimates of HardyWeinberg equilibrium were evaluated using chi-square tests. Logistic regression modeling was used to determine the association between the independent effect of rs3735590 SNP and the interaction between genotype, PON1 activity, and other covariates on lipids and CAVS risk. All statistical analyses were performed using SPSS, version 17.0.1 for Windows (SPSS Inc., Chicago, IL). A p value of $<0.05$ was considered significant for all analyses. Results: This study confirmed that PON1 is a validated target gene of miR-616 in liver cells. The relative quantification representing the expression of PON1 mRNA and the serum level of PON1 protein was decreased in the TT genotype. Moreover, the expression of PON1 had a negative regulatory relationship with the expression of miR-616 $(r=-0.3959, \mathrm{P}<0.05)$ in human tissues. The patients with CT OR TT genotype at loci rs3735590 had a lower risk of CAVS than patients with the CC genotype. Conclusions: Our results suggest that functional SNP in the $3^{\prime} U T R$ of PON1 regulates the expression of PON1 via miR-616, and such SNP is associated with the risk of CAVS in human.

Z. Wang and S. Chen contributed equally to this work.




\section{Introduction}

Calcific aortic valve stenosis (CAVS) is a common medical condition influencing $25 \%$ of the population over age 65 and $50 \%$ of the population over age 85 [1]. CAVS is characterized pathologically by calcification, thickening, and fibrosis of the aortic valve leaflets without remarkable neovascularization, which is the feature of rheumatic aortic valve diseases [2]. Functionally, there are two stages in the pathogenesis of calcific aortic valve stenosis: aortic sclerosis and aortic stenosis. Valve leaflet thickening and calcification are presented in aortic sclerosis; however, the leaflet mobility is not impaired to substantially limit the flow of blood [3]. By contrast, aortic stenosis is characterized by the presence of leaflet mobility, which has become significantly restricted to impede left ventricular outflow [4].

MicroRNAs (miRNAs) are a class of non-coding RNA with about 18 22 nucleotides in length. MiRNAs participate in post transcriptional regulation by binding to the 3 ' untranslated region (UTR) in their target genes [5]. MiRNAs participate in diverse biological processes, such as oncogenesis, atherosclerosis, and embryonic development $[5,6]$. In particular, some miRNAs (e.g., let-7 and miR-29b) play a critical role in the process of atherosclerosis [7]. In the human genome, single nucleotide polymorphisms (SNPs) are the most common manifestation of DNA variation [8]. Genetic repression induced by miRNA could be affected by SNPs located in the 3'UTR of the target mRNA [9] . MiR-SNP is defined as SNP affecting the binding of miRNA to its target genes [10]. Consequently, a miR-SNP exerts influence on disease susceptibility by affecting the expression of relevant genes [11].

Genetic predisposition is associated with CAVS development [12] . A familial aggregation for CAVS has been reported by Probst et al. [13]. Polymorphisms in the vitamin D receptor are very common in patients with CAVS [14]. Polymorphism in the NOTCH1 receptor is associated with calcification of the aortic valve in patients with CAVS and other congenital heart abnormalities [15]. Wypasek et al. reported that the polymorphisms in IL6R or CRP were associated with CAVS $[16,17]$. In addition, it has been reported that two protein polymorphisms, L55M and Q192R, played an important role in the activity of paraoxonase1 (PON1), which is associated with the susceptibility to CAVS [18].

Recently, It was reported that rs3735590, a miR-SNP located within the PON1 gene, was involved in the pathogenesis of atherosclerosis and the SNP could alter the risk of atherosclerosis by affecting the binding of miR-616 to its target mRNA of PON1 [19]. As miRNAs play a regulatory role in gene expression, miR-SNPs could act as promising markers to identify the risks of CAVS. In this study, we investigated the role of SNP, which is located in the 3'UTR of PON1, in the regulation of PON1 expression via miR-616. In addition, we also confirmed that the SNP in the 3'UTR was also associated with the risk of CAVS.

\section{Materials and Methods}

\section{Research ethics}

The research protocol was approved by the Institutional Review Board at Shandong Provincial Hospital Affiliated to Shandong University. According to Helsinki Declaration, patients and participants were educated regarding the protocol and their informed consent was obtained.

\section{Study population}

459 participants, including 216 CAVS patients and 243 CAVS-free participants, were recruited in this study. The 216 CAVS patients were recruited from the inpatient and outpatient departments of Cardiovascular Surgery, Shandong Provincial Hospital Affiliated to Shandong University. Those patients with a history of CAD (myocardial infarction and/or angiographically demonstrated coronary artery stenosis), aortic valve surgery, congenital cardiac disease (bicuspid aortic valve), and active or chronic liver diseases were excluded from the study. Additional exclusion criteria included echocardiographic evidence of rheumatic mitral valve disease, subaortic obstruction, and a creatinine concentration of $\geq 2.0 \mathrm{mg} / \mathrm{dL}$. We also recruited 243 participants with matched genders and age. The demographic and clinicopathological characteristics 
of these participants were presented in Table 1.

\section{Genotyping}

Genotyping was conducted according to a SNP genotyping method and using a TaqMan probe-based assay (Cat. \# 4351379). In brief, polymerase chain reaction (PCR) primers and TaqMan minor groove binder (MGB) probes were purchased from Applied Biosystems (Foster City, CA), and the reactions were performed in 96-well microplates on an ABI 7900 thermal cycler (Applied Biosystems, Foster City, CA). Fluorescence was measured using an ABI 7900 Real Time PCR System (Applied Biosystems, Foster City, CA) and analyzed using System SDS software version 1.2.3.

\section{Western blot analysis}

Lysates of individual cells (10 ug / lane) were separated by sodium dodecyl sulfate polyacrylamide gel (SDS-PAGE, $10 \%$ ) electrophoresis and transferred onto nitrocellulose membranes (Millipore Corporation, Billerica, MA). The membranes were then incubated in a SuperBlock T20 PBS Blocking Buffer (Thermo Fisher Scientific Inc., Waltham, MA). Subsequently, the membranes were incubated with primary antibodies (anti-PON1 antibody, 1:1000, and anti-beta-actin antibody, 1:10000, Cell Signaling Technology) according to the manufacturer's instructions. The bound antibodies were detected with a horseradish peroxidaseconjugated secondary antibody (1:5000, Cell Signaling Technology). Working solutions of the Pierce ECL Substrate and GE Healthcare ECL Reagent (Thermo Fisher Scientific) were prepared according to the manufacturers' instructions. The membranes were digitally imaged using an enhanced chemiluminescence system.

\section{Quantitative Real-Time Polymerase Chain Reaction ( $q P C R$ )}

Total RNA was extracted with TRIzol (Invitrogen) for qPCR.SYBRGreen qPCR(Takara Bio Inc.,Otsu, Japan) was performed. For miRNA, qPCR primers were designed and purchased from Gene Pharma (Shanghai, China). U6 or $\beta$-actin was used as the endogenous control of miR-616 and PON1 mRNA, respectively. The expression of target genes was quantified in 6 replicates using a One Step SYBR PrimeScript RT-PCR Kit II (Takara) on an ABI Step One Real-Time PCR System (Applied Biosystems, Foster City, CA). The qPCR was performed with conventional protocols using the following primer sets: PON1: 5'-TGTTCACTTCGATGACTGG-3' and 5'-CAGTGTAGTCTTTGGGGACA-'3,miR-616: 5'-GGTGGTAGTGAATTGATCTAGATTGGAAA-3'. The expression level of the target genes relative to the control was determined using the $2^{\wedge} \Delta \triangle \mathrm{CT}$ method.

\section{Collection of Liver Tissue Samples}

48 liver tissue samples were collected from hepatocarcinoma patients who have received surgical intervention at Shandong Provincial Hospital Affiliated to Shandong University, and were genotyped for the polymorphism.

\section{Cell Culture, Stimulation, and Transfection}

The HepG2 cell line was purchased from ATCC, and the cells were cultured at $37^{\circ} \mathrm{C}$ under a $5 \% \mathrm{CO}_{2}$ atmosphere in DMEM tabemented with penicillin/streptomycin and 10\% FBS. The miR-616 mimics and inhibitor, as well as PON1 siRNA, were purchased from Ambion (Austin, TX). 


\section{Cellular Physiology Cell Physiol Biochem 2018;45:1390-1398 \begin{tabular}{l|l|l} 
and Biochemistry Published onlIne: February 202018 & $\begin{array}{l}\text { C } 2018 \text { The Author(s). Published by S. Karger AG, Basel } \\
\text { www.karger.com/cpb }\end{array}$ \\
\hline
\end{tabular}}

Wang et al.: PON1 is Associated with CAVS

\section{Biochemistry}

In accordance with standard institutional protocols, blood was drawn after 12-hour of fasting for routine clinical biochemistry tests in Shandong Provincial Hospital Affiliated to Shandong University. Inhospital audit have previously demonstrated that the variability in sample results was between $5 \%$ and $15 \%$ for these assays (data not shown).

\section{Echocardiography}

Comprehensive transthoracic echocardiograms were obtained using an echocardiography instrument(Philips IE33,Philips Electronics Ltd, Netherland) at the Department of Ultrasound in Shandong Provincial Hospital Affiliated to Shandong University. All participants, including echocardiogram performers and interpreters, were blinded to the status of patient treatment. Standard Doppler parameters including ejection fraction (EF) and aortic valve area were recorded. Reproducibility of the echocardiography performed by two cardiologists was assessed using a 30-patient subset. All examined echocardiography parameters showed intra-class coefficient correlations (ICCs) of between 0.961 and 0.991 (intra-observer), and between 0.951 and 0.990 (inter-observer).

\section{Serum PON1 Level}

Serum PON1 level was determined using paraoxon (Aldrich Chemical Co, St.Louis, MO). The assay buffer was prepared with $0.132 \mathrm{mM}$ Tris- $\mathrm{HCl}, \mathrm{pH} 8.5$, and $1.32 \mathrm{mM} \mathrm{CaCl}_{2}$. Each set of assays used $6 \mathrm{mM}$ freshly prepared paraoxon substrate solution ( $120 \mathrm{mM}$ paraoxon in acetone diluted with $0.132 \mathrm{mM}$ Tris $-\mathrm{HCl})$. The assay tube contained $152 \mu \mathrm{l}$ Tris buffer, $8 \mu \mathrm{l}$ serum (1:2 diluted with water), and $40 \mu \mathrm{l} 6$-mM paraoxon. The reaction was initiated at $37.8^{\circ} \mathrm{C}$ by adding the substrate solution; absorbance was continuously monitored at $405 \mathrm{~nm}$. A molar extinction coefficient of $18.05 \times 10^{3}$ was obtained and used to evaluate the activity of PON1, and the results were expressed as U/L.

\section{Luciferase Reporter Assay}

A luciferase reporter assay system and cloning kits were purchased from Promega Corporation (Madison, WI). Lipofectamine 2000 was purchased from Invitrogen (Carlsbad, CA). HepG2 genomic DNA was isolated and the full length 3'UTR of PON1 was amplified using PCR. The PCR products were cloned into the downstream segment of the luciferase gene in the pMIR-REPORT luciferase vector (Ambion) to generate pMIR-PON1-3'UTR. Site-directed mutagenesis of the miR- 616 target site in the PON1 3'UTR was performed using the Quick Change Site-Directed Mutagenesis Kit (Stratagene, Heidelberg, Germany). The vector harboring the mutant miR-616 binding site was named as pMIR-PON1-3'UTR-mutant. For reporter assays, cells were transiently transfected with reporter plasmids harboring the original or mutated sequences of PON1 and the miR-616 mimic using Lipofectamine 2000 (Invitrogen). The plasmid containing renilla luciferase was co-transfected as the internal control. After $24 \mathrm{~h}$ of transfection, the cells were assayed for luciferase activity using the Dual-Luciferase Reporter Assay System (Promega) according to the manufacturer's instructions.

\section{Statistical analysis}

Patient characteristics are presented as mean \pm standard deviation (SD) for normally distributed and continuous variables; categorical variables are expressed as frequencies (percentages). Continuous variables were assessed using Kolmogorov-Smirnov test to verify the assumption of normality. Differences in baseline characteristics between CAVS patients and controls were compared using independent $t$ tests for normally distributed and continuous variables. Mann-whitney U tests were used to compare non-normally distributed continuous variables, whereas chi-square tests were used to compare categorical variables. Differences between the groups were compared using one-way ANOVA or independent t-tests. Differences between CVAS patients and controls in terms of genotype frequency distribution and the estimates of Hardy-Weinberg equilibrium were evaluated using chi-square tests. Logistic regression modeling was used to determine the association between the independent effect of rs3735590 SNP and the interaction between genotype, PON1 activity, and other covariates on lipids and CAVS risk. All statistical analyses were performed using SPSS, version 17.0.1 for Windows (SPSS Inc., Chicago, IL). A p value of $<0$.05 was considered significant for all analyses. 


\section{Results}

PON1 is a target gene of miR-616 in liver cells.

Based on the results of computational analysis, the SNP in the 3'UTR of PON1 was located within the binding site for hsa-miR-616 (Fig. 1). To test if hsa-miR-616 targets PON1 in liver cells, we constructed reporter vectors carrying wild-type or mutant PON1 3'UTR, as described in Fig. 2. The luciferase activity of cells harboring wild-type PON1 3'UTR and miR616 mimics was significantly lower than that of the controls, whereas the luciferase activity of cells harboring mutant PON1 3'UTR and miR-616 showed no difference from that of the controls. These data confirmed that PON1 is a validated target gene of miR-616 in liver cells.

\section{Expression of PON1 in the liver tissues of TT genotype was inhibited}

Liver tissues of three different genotypes (CC, $n=28, C T, n=16, T T, n=4)$ were used to further explore the impact of PON1 3'UTR polymorphism on the regulation of PON1 expression via miR-616. Using qPCR, we found the expression of miR-616 was comparable among all groups (Fig. 3). Meanwhile, the mRNA level of PON1 (Fig. $4 \mathrm{~A}$ ) and the serum level of PON1 protein (Fig. 4B) were decreased in the TT group as compared with those in the CC and CT groups. The correlation analysis of human liver tissues showed that miR-616 and PON1 had a negative regulatory relationship ( $r=-0.3959$, $p<0.05$, Fig. 5).

\section{SNP in 3'UTR regulated PON1} expression via miR-616

To further validate the negative regulatory relationship between miR-616 and the SNP of PON1, we preformed an in vitro study using liver cells. As shown in Fig. 6, the expression of PON1 protein (Fig. 6A) and mRNA (Fig. 6C) in the presence of WT 3'UTR was significantly down-regulated by miR-616 mimics and PON1 siRNA. Meanwhile, the treatment with miR-616 inhibitors significantly increased the protein (Fig. 6A) and mRNA level of PON1 (Fig. 6C). The mutant PON1 showed a different response pattern in the presence of miR-616 mimics. As shown in Fig. $6 \mathrm{~B}$ and 6D, the miR-616 mimics lost their ability to inhibit the expression of PON1. The results indicated that miR-616 inhibits the expression of wild type PON1, but not the expression of mutant PON1 in liver cells.

MiR-SNP of PON1 loci rs3735590 was associated with the risk of CAVS.

We next evaluated the association between the miR-SNP of loci rs3735590 in

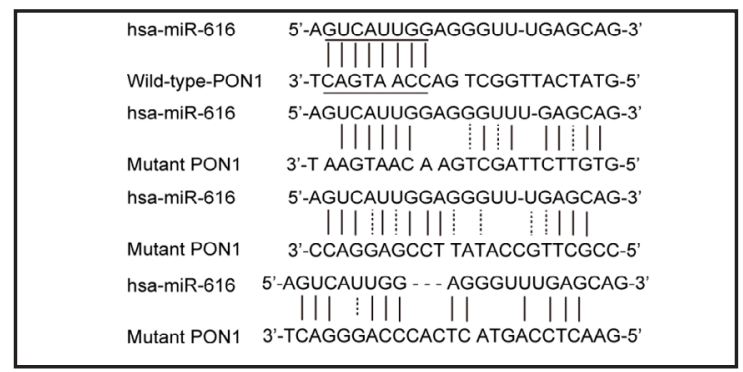

Fig. 1. SNP of the 3'UTR of PON1 is located within the predicted binding site of hsa-miR- 616 .

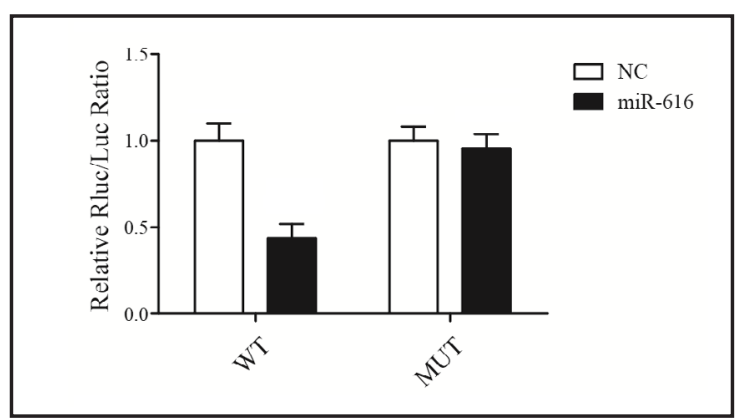

Fig. 2. miR-616 recognizes the $3^{\prime} \mathrm{UTR}$ of PON1 in liver cells.

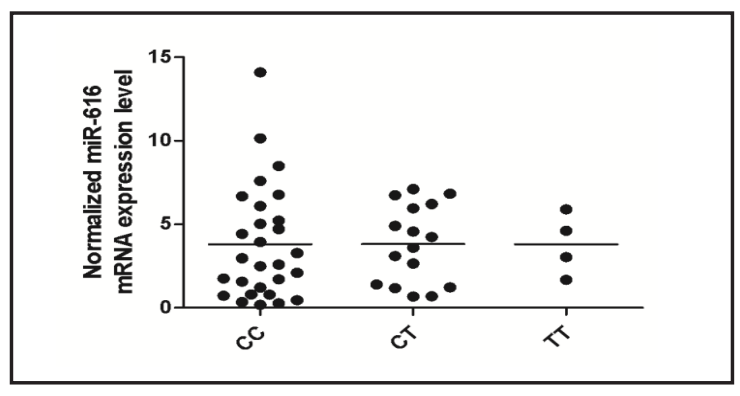

Fig. 3. Expression level of miR-616 showed no significantly changes in three different genotypes. CC, $\mathrm{n}=28, \mathrm{CT}, \mathrm{n}=16, \mathrm{TT}, \mathrm{n}=4$. 
the PON1 gene and the risk of CAVS in 216 CAVS patients and 243 CAVS-free participants. As shown in Table 1, the average age (in years) and its standard deviations (SD) in CAVS patients and healthy participants were $72.2 \pm 9.6$ and $72.6 \pm$ 10.2 , respectively. As expected, the level of total cholesterol and LDL was higher in CAVS patients than that in healthy participants $(\mathrm{p}<0.0001)$, whereas the activity of HDL and PON1 was lower in CAVS patients than that in healthy participants $(\mathrm{p}<$ 0.0001). The genotype distribution of PON1 loci rs3735590 reached Hardy-Weinberg equilibrium. The logistic regression analysis with adjusted potential confounding factors, such as age, gender, BMI, blood pressure, lipid and cardiac function, showed that the patients with CT or TT genotype at loci rs3735590 had a lower risk of CAVS than patients with the CC genotype (OR: 1.81, 95\%, 1.162.83, $\mathrm{P}=0.0085$ ).

\section{Discussion}

As an anti-atherogenic mediator, high-density lipoprotein (HDL) not only plays a key role in the reverse transport of cholesterol, but also prevents the oxidation of LDL and HDL [20]. HDL's antioxidant property is partially mediated by the function of PON1 enzyme [21]. LDL oxidation and reduced HDL promote the progress of CAVS. Since PON1 protects the aortic valve from the damaging effect of degenerative processes by inhibiting LDL oxidation, a decreased level of PON1 activity leads to an increased level of oxidative stress and inflammation, which in turn trigger an accelerated process of valve degeneration and stenosis [21]. Dyslipidemia was considered to be an important risk factor contributing to the development of CAVS [12]. PON1 plays an important role in lipid

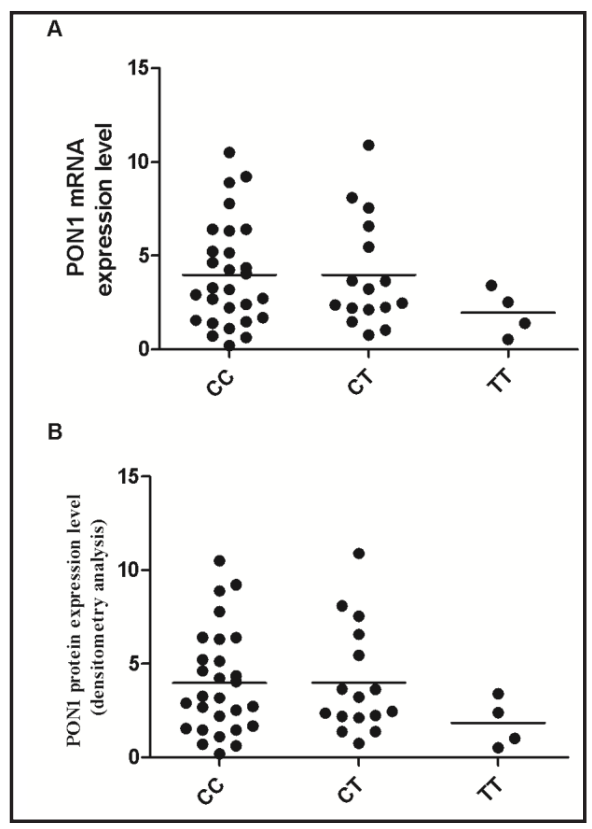

Fig. 4. Level of PON1 mRNA (A) and serum PON1 protein (B) was significantly lower in the TT genotype. CC, $n=28, C T, n=16$, TT, $\mathrm{n}=4$.

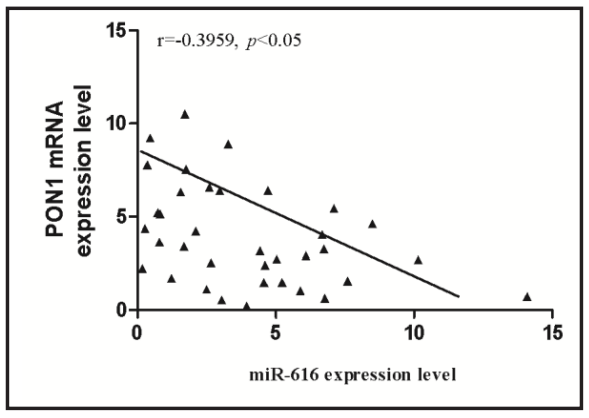

Fig. 5. Expression of miR-616 and PON1 mRNA showed a negative regulatory relationship in the tissues. metabolism, whereas the dysregulation of PON1 is responsible for the pathogenesis of dyslipidemia [18]. In addition, dyslipidemia is also considered a risk factor of CAVS [18]. Based on the results from the computational analysis, we identified PON1 as a possible target gene of miR-616. Furthermore, we also used a luciferase reporter system to validate that PON1 is a direct target gene of miR-616 in liver cells.

Paraoxonases (PONs, consisting of PON1, PON2 and PON3) are synthesized in the liver and transported through the systemic circulation. It is an aryldialkyl phosphatase and exclusively interacts with the HDL sub-fraction [22-24]. After binding to HDL, PON1 promotes the biological degradation of oxidized lipids in LDL and inhibits the peroxidation of lipids [25] . PON1 is also recruited for the breakdown of lipid peroxides before their accumulation on LDL [26] . The overexpression of PON1 was shown to provide protection against atherosclerosis in a mouse model [27]. Meanwhile, the activity of PON1 is decreased in many diseases, such as slow coronary flow [28], cardiac syndrome X [29], CAD [30], diabetes mellitus, and myocardial infarction [31]. In addition, the level of serum PON1 is inversely 


\section{Cellular Physiology Cell Physiol Biochem 2018:45:1390-1398

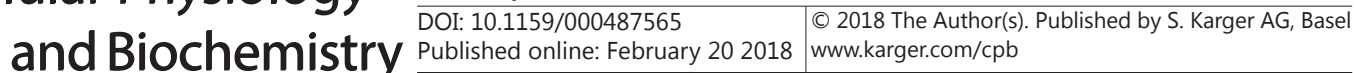

associated with diabetes, hypercholesterolemia and coronary artery disease (CAD) [24, 32]. Previous studies have shown that the changes in the level of serum PON1 may occur, regardless of the changes in HDL cholesterol [33, 34]. Recently, Navab et al. showed that the oxidation of LDL was not blocked by HDL in patients with CAD because of a low level of serum PON1, even though the concentration of HDL in these patients was relatively normal [35] . LDL oxidation and a reduced level of HDL promote the pathogenesis of CAVS. As PON1 protects the aortic valve against degenerative processes by inhibiting LDL oxidation, the declined level of serum PON1 can lead to increased oxidative stresses and inflammation, which in turn trigger an accelerated process of aortic valve degeneration and stenosis.

In the past decade, several groups have studied the association between the SNPs in the PON1 gene cluster and the susceptibility to atherosclerosis. However, conflict findings have been reported. The PON1 genotype Gln192Arg (Q192R) SNP was closely associated with the onset of stroke in CARE trial patients [36], and the activity of serum PON1 was lower in patients with CAVS and was inversely correlated with the severity of CAVS [37]. In this study, we tested the hypothesis that PON1 genetic variants are associated with the risk of CAVS. The loci rs3735590 of PON1 3'UTR contains the binding site of miR-616. A substitution of C by T has resulted in non-complementarity between PON1 mRNA and miR-616. In contrast, the $\mathrm{C}$ allele decreased the expression of PON1. Furthermore, the liver tissues harboring three different genotypes (CC, $n=28, C T, n=16, T T, n=4$ ) were used to explore the impact of polymorphism on the interaction between miR-616 and PON1 3'UTR. Using qPCR, we found that the expression of miR-616 was similar among these groups (Fig. 3). However, the expression of PON1 mRNA (Fig. 4A) and protein (Fig. 4B) decreased in the TT group but not in the CC group, indicating that the presence of the minor allele could compromise the interaction between miR-616 and the 3'UTR of PON1. As a negative regulator of PON1, upregulation of miR-616 inhibited the expression of its target gene, PON1, by binding to the 3'UTR of the mRNA, whereas the substitution of the nucleotide, as a result of single nucleotide polymorphism, could disrupt the binding of miR-616 to the 3'UTR and restore the expression of PON1. The in vivo correlation analysis showed a negative regulatory relationship between miR-616 and PON1 ( $\mathrm{r}=-0.3959, \mathrm{P}<0.05)$ in human liver tissues. Furthermore, using a logistic regression analysis with adjusted confounding factors, our clinical study showed that the patients harboring the CT or TT genotype at loci rs3735590 were associated with a lower risk of CAVS than the patients harboring the CC genotype (OR: 1.81, 95\%, 1.16-2.83, P=0.0085). Some variants located in the C-reactive protein or interleukin-6 have been shown to affect the susceptibility to CAVS. The rs3735590 polymorphism compromised the interaction between miRNA and mRNA, whereas miR-616 restored the expression of PON1, suggesting that such SNP may be associated with the risk of CAVS. 


\section{Cellular Physiology Cell Physiol Biochem 2018;45:1390-1398

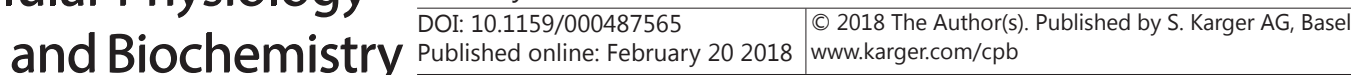

Wang et al.: PON1 is Associated with CAVS

\section{Conclusion}

In summary, these findings demonstrated that rs3735590 in the 3'UTR of PON1 disrupted the binding of PON1 with miR-616, thus increasing the level of HDL and reducing the risk of CAVS.

\section{Acknowledgements}

The study was supported by Science and Technology Department of Shandong Province (No. ZR2013HM056 and No.2016GSF201039).

\section{Disclosure Statement}

No conflict of interests exists.

\section{References}

1 Stewart BF SD, Lind BK,Gardin JM,Gottdiener JS,Smith VE, Kitz-man DW,Otto CM: Clinical factors associated with calcific aortic valve disease. J Am Coll Cardiol 1997;29: 630-634.

2 Roberts WC: Anatomically isolated aortic valvular disease. Am J Med 1970;49:151-159.

-3 Otto CM, Burwash IG, Legget ME, Munt BI, Fujioka M, Healy NL, Kraft CD, Miyake-Hull CY, Schwaegler RG: Prospective study of asymptomatic valvular aortic stenosis : Clinical, echocardiographic, and exercise predictors of outcome. Circulation 1997;95:2262-2270.

-4 Otto CM, Pearlman AS, Gardner CL, Enomoto DM, Togo T, Tsuboi H, Ivey TD: Experimental validation of doppler echocardiographic measurement of volume flow through the stenotic aortic valve. Circulation 1988;78:435-441.

5 Ambros V: The functions of animal micrornas. Nature 2004;431: 350-355.

6 Chen KC, Juo SH: Micrornas in atherosclerosis. Kaohsiung J Med Sci 2012;28: 631-40.

7 Chen KC, Liao YC, Hsieh IC, Wang YS, Hu CY, Juo SH: Oxldl causes both epigenetic modification and signaling regulation on the microrna-29b gene: Novel mechanisms for cardiovascular diseases. J Mol Cell Cardiol 2012;52:587-595.

8 Bernig T,Chanock SJ: Challenges of snp genotyping and genetic variation: Its future role in diagnosis and treatment of cancer. Expert Rev Mol Diagn 2006;6:319-331.

-9 Brodersen P, Voinnet 0: Revisiting the principles of microrna target recognition and mode of action. Nat Rev Mol Cell Biol 2009;10:141-148.

10 Mishra PJ, Humeniuk R, Mishra PJ, Longo-Sorbello GS, Banerjee D, Bertino JR: A mir-24 microrna bindingsite polymorphism in dihydrofolate reductase gene leads to methotrexate resistance. Proc Natl Acad Sci USA 2007;104:13513-13518.

11 Sethupathy P, Collins FS: Microrna target site polymorphisms and human disease. Trends Genet 2008;24:489-497.

12 Rajamannan NM: Calcific aortic stenosis: Lessons learned from experimental and clinical studies. Arterioscler Thromb Vasc Biol 2009;29:162-168.

13 Probst V, Le Scouarnec S, Legendre A, Jousseaume V, Jaafar P, Nguyen JM, Chaventre A, Le Marec H, Schott JJ: Familial aggregation of calcific aortic valve stenosis in the western part of france. Circulation 2006;113:856860.

14 Ortlepp JR HR, Ohme F, Lauscher J, Bleckmann F, Hanrath P: The vitamin d receptor genotype predisposes to the development of calcific aortic valve stenosis. Heart 2001;85:635-638.

15 Garg V, Muth AN, Ransom JF, Schluterman MK, Barnes R, King IN, Grossfeld PD, Srivastava D: Mutations in notch1 cause aortic valve disease. Nature 2005;437:270-274.

16 Wypasek E, Potaczek DP, Undas A: Association of the c-reactive protein gene (crp) rs1205 c>t polymorphism with aortic valve calcification in patients with aortic stenosis. Int J Mol Sci 2015;16:2374523759. 


\section{Cellular Physiology Cell Physiol Biochem 2018;45:1390-1398 \begin{tabular}{ll|l} 
DOI: 10.1159/000487565 202018 & $\begin{array}{l}\text { O } 2018 \text { The Author(s). Published by S. Karger AG, Basel } \\
\text { www.karger.com/cpb }\end{array}$ \\
and Biochemistry Published online: February 2020 &
\end{tabular}}

Wang et al.: PON1 is Associated with CAVS

17 Wypasek E, Potaczek DP, Lamplmayr M, Sadowski J, Undas A: Interleukin-6 receptor asp358ala gene polymorphism is associated with plasma c-reactive protein levels and severity of aortic valve stenosis. Clin Chem Lab Med 2014;52: 1049-1056.

18 Moura LM, Faria S, Brito M, Pinto FJ, Kristensen SD, Barros IM, Rajamannan N, Rocha-Gonçalves F: Relationship of pon 192 and 55 gene polymorphisms to calcific valvular aortic stenosis. Am J Cardiovasc Dis 2012;2:123-132.

19 Liu ME, Liao YC, Lin RT, Wang YS, Hsi E, Lin HF, Chen KC, Juo SH: A functional polymorphism of pon1 interferes with microrna binding to increase the risk of ischemic stroke and carotid atherosclerosis. Atherosclerosis 2013;228:161-167.

-20 Mackness MI AS, Abbott C,Durrington PN: Protection of low-density lipoprotein against oxidative modification by high-density lipoprotein associated paraoxonase. Atherosclerosis 1993;104:129-135.

21 Navab M,Berliner JA,Watson AD,Hama SY,Territo MC,Lusis AJ,Shih DM,Van Lenten BJ,Frank JS,Demer LL,Edwards PA: The yin and yang of oxidation in the development of the fatty streak. A review based on the 1994 george lyman duff memorial lecture. Arterioscler Thromb Vasc Biol 1996;16:831-842.

-22 Blatter MC JR, Messmer S,Barja F,Pometta D: Identification of a distinct human high-density lipoprotein subspecies defined by a lipoprotein-associated protein, k-45. Identity of k-45 with paraoxonase. Eur J Biochem 1993;211:871-879.

-23 Kelso GJ SW, Richter RJ,Furlong CE,Jordan-Starck TC,Harmony JA Apolipoprotein j is associated with paraoxonase in human plasma. Biochemistry 1994;33:832-839.

24 McElveen J MM, Colley CM, Peard T, Warner S, Walker CH: Distribution of paraoxon hydrolytic activity in the serum of patients after myocardial infarction. Clin Chem 1986;32:671-673.

-25 Barter PJ, Nicholls S, Rye KA, Anantharamaiah GM, Navab M, Fogelman AM: Antiinflammatory properties of hdl. Circ Res 2004;95:764-772.

-26 Mackness MI AS, Durrington PN: Paraoxonase prevents accumulation of lipoperoxides in low-density lipoprotein. FEBS Lett 1991;286:152-154.

-27 Tward A: Decreased atherosclerotic lesion formation in human serum paraoxonase transgenic mice. Circulation 2002;106:484-490.

-28 Yildiz A, Gur M, Yilmaz R, Demirbag R, Polat M, Selek S, Celik H, Erel O: Association of paraoxonase activity and coronary blood flow. Atherosclerosis 2008;197:257-263.

-29 Gur M,Yildiz A,Demirbag R,Yilmaz R,Aslan M,Ozdogru I,Erel O: Paraoxonase and arylesterase activities in patients with cardiac syndrome $\mathrm{x}$, and their relationship with oxidative stress markers. Coron Artery Dis 2007;18:89-95.

-30 Azarsız E, Kayıkcıoğlu M, Payzın S, Yıldırım Sözmen E: Pon1 activities and oxidative markers of ldl in patients with angiographically proven coronary artery disease. Int J Cardiol 2003;91:43-51.

31 Ayub A, Mackness MI, Arrol S, Mackness B, Patel J, Durrington PN: Serum paraoxonase after myocardial infarction. Arterioscler Thromb Vasc Biol 1999;19:330-335.

-32 Mackness MI, Harty D, Bhatnagar D, Winocour PH, Arrol S, Ishola M, Durrington PN: Serum paraoxonase activity in familial hypercholesterol- aemia and insulin-dependent diabetes mellitus. Atherosclerosis 1991;86: 193-199.

-33 Mackness MI,Mackness B,Durrington PN,Connelly PW,Hegele RA: Paraoxonase: Biochemistry, genetics and relationship to plasma lipoproteins. Curr Opin Lipidol 1996;7: 69-76.

-34 Mackness B,Durrington PN,Mackness MI: Human serum paraoxonase. Gen Pharmacol 1998;31: 329-336.

-35 Navab M, Hama-Levy S, Van Lenten BJ, Fonarow GC, Cardinez CJ, Castellani LW, Brennan ML, Lusis AJ, Fogelman AM: Mildly oxidized ldl induces an increased apolipoprotein j/paraoxonase ratio. J Clin Invest 1997;99:2005-2019.

-36 Ranade K, Kirchgessner TG, Iakoubova OA, Devlin JJ, DelMonte T, Vishnupad P, Hui L, Tsuchihashi Z, Sacks FM, Sabatine MS, Braunwald E, White TJ, Shaw PM, Dracopoli NC: Evaluation of the paraoxonases as candidate genes for stroke: Gln192arg polymorphism in the paraoxonase 1 gene is associated with increased risk of stroke. Stroke 2005; 36: 2346-2350.

37 Maganti K, Rigolin VH, Sarano ME, Bonow RO: Valvular heart disease: Diagnosis and management. Mayo Clin Proc 2010;85:483-500. 